\section{Therapeutic approaches to cerebral vasospasm complicating ruptured aneurysm}

\author{
Mohamed Barbarawi, 'Sarah F. Smith, ${ }^{2}$ \\ Mohamed Abu Jamous,' Hazem Haboub, ${ }^{3}$ \\ Qudsieh Suhair, ${ }^{4}$ Shboul Abdullah'
}

'Department of Neurosurgery, ${ }^{3}$ Department of Radiology; King Abdullah University Hospital, Jordan University of Science and Technology, Irbid, Jordan; 2Department of Neurosurgery Royal North Shore Hospital St. Leonards, Australia; ${ }^{4}$ Hashemite University, Faculty of Medicine, Zarqa, Jordan

\section{Abstract}

Cerebral vasospasm is a serious complication of ruptured aneurysm. In order to avoid short- and long-term effects of cerebral vasospasm, and as there is no single or optimal treatment modality employed, we have instituted a protocol for the prevention and treatment of vasospasm in patients suffering aneurysmal sub-arachnoid hemorrhage (SAH). We then reviewed the effectiveness of this protocol in reducing the mortality and morbidity rate in our institution. In this study we present a retrospective analysis of 52 cases. Between March 2004 and December 200852 patients were admitted to our service with aneurysmal SAH. All patients commenced nimodipine, magnesium sulphate $\left(\mathrm{MgSO}_{4}\right)$ and triple $\mathrm{H}$ therapy. Patients with significant reduction in conscious level were intubated, ventilated and sedated. Intracranial pressure (ICP) monitoring was used for intubated patients. Sodium thiopental coma was induced for patients with refractory high ICP; angiography was performed for diagnosis and treatment. Balloon angioplasty was performed if considered necessary. Using this protocol, only 13 patients (25\%) developed clinical vasospasm. Ten of them were given barbiturates to induce coma. Three patients underwent transluminal balloon angioplasty. Four out of 52 patients (7.7\%) died from severe vasospasm, 3 patients (5.8\%) became severely disabled, and 39 patients $(75 \%)$ were discharged in a condition considered as either normal or near to their pre-hemorrhage status. Our results confirm that the aforementioned protocol for treatment of cerebral vasospasm is effective and can be used safely.

\section{Introduction}

Cerebral vasospasm (CV) is the most significant cause of high mortality and morbidity in patients suffering aneurysmal sub-arachnoid hemorrhage (SAH); but it may also occur after head injury. ${ }^{1}$ The precise pathogenesis of vasospasm is still poorly understood but seems to be related to the products of the erythrocyte breakdown. $^{2}$ This entity is a multifactorial problem and is highly correlated with poor clinical grade at presentation and the amount of blood in the subarachnoid space. The site of the aneurysm, the presence of hypotension, hyponatremia, hypovolemia, hyperthermia, high intracranial pressure, intraventricular hemorrhage, the use of antifibrinolytic agents, smoking, and the age of the patient are also considered as risk factors for $\mathrm{CV}^{3-6}$

Typically, CV occurs on about the fourth day after SAH and usually peaks between seven and ten days. Diffuse or worsening headache with irritability are usually the initial symptoms; altered level of consciousness and the appearance of a new focal neurological deficit are other hallmarks of clinical vasospasm. Multimodal treatments for $\mathrm{CV}$ have been adopted by various institutions, but no consensus has yet been reached on the optimal protocol. ${ }^{8}$ Here we introduce the protocol used in our practice to deal with patients suffering from ruptured aneurysm and at risk of developing clinical vasospasm, and then discuss the results obtained from applying this protocol over the last four years. In comparison with other protocols used we concluded that our protocol is safe and effective. ${ }^{9,10}$

\section{Materials and Methods}

The study was approved by the ethical committee for human research (IRB) at Jordan University of Science and Technology. Our study population consisted of 52 patients treated only for aneurysmal SAH in King Abdullah University Hospital between March 2004 and April 2008 (Table 1). The diagnosis was based on the clinical presentation of ruptured aneurysm, a CT scan positive for $\mathrm{SAH}$, and the presence of aneurysm on digital subtraction angiography (DSA). Lumbar puncture to check for erythrocytes or xanthochromia in the CSF was also considered in patients with a history highly suggestive of ruptured aneurysm and a negative CT scan for SAH. Patients with head trauma, unruptured aneurysm or a DSA negative for aneurysm were excluded from this study.

The World Federation of Neurosurgical Society (WFNS) Glasgow Coma Scale (GCS) grading system ${ }^{3}$ was applied to assess all
Correspondence: Mohamed Barbarawi, Department of Neuroscience, Division of Neurosurgery, King Abdullah University Hospital,

Jordan University of Science and Technology,

P.0. Box (630001) (22110) Irbid, Jordan

E-mail: dr_barbarawi@yahoo.com

Key words: cerebral vasospam, ruptured aneurysm.

Received for publication: 29 March 2009.

Revision received: 20 June 2009.

Accepted for publication: 23 September 2009.

This work is licensed under a Creative Commons Attribution 3.0 License (by-nc 3.0).

(C) Copyright M. Barbarawi et al., 2009

Licensee PAGEPress, Italy

Neurology International 2009; 1:e13

doi:10.4081/ni.2009.e13

patients neurologically. Thirty- two patients (61.5\%) were classified as grade 1, 9 patients (17.4\%) as grade 2 , and 5 patients $(9.6 \%)$ as grade 3 ; the remaining (11.5\%) were grades 4 and 5 . Of these, one patient evolved from grade 1 to 5 before she arrived at our service after rebleeding.

The Fisher grading system was applied to the study group to correlate the amount of blood seen on the CT scan with the risk of vasospasm. ${ }^{4}$ One patient ranked grade 1 as the CT scan was negative for bleeding and the CSF was positive for xanthochromia, the majority of patients were categorized grade 2 and 3 , and only 3 patients (5.8\%) were assessed as Fisher grade 4 . The standard procedure in this institution is for early aneurysm repair by coiling or clipping within the first three days of rupture. Most patients in the study underwent early repair except 6 (11.5\%) in whom the aneurysm was repaired late (between days 12 and 14) as the patients arrived at our hospital service two days after the ictus; in those patients we chose to repair the aneurysm after the peak of the vasospasm when coiling was not applicable. The cranial orbito-zygomatico-pterional transsylvian approach was selected to deal with 18 patients (34.6\%) for direct clipping; while the patient with giant aneurysm (1.9\%) underwent the same approach for resection and aneurysmorrhaphy with reinforcement. Endovascular coiling was effected in 31 patients $(59.6 \%)$ including those with basilar tip aneurysm. Two patients (3.9\%) had no intervention as they were in a moribund condition.

\section{Protocol used for the management of cerebral vasospasm}

Once the diagnosis of aneurysmal SAH was made, the following protocol was applied from the time of admission as a preventive measure 
Table 1. Demographic details.

\begin{tabular}{lll}
\hline \multirow{2}{*}{ Sex } & Males & $28(53.8 \%)$ \\
& Females & $24(46.2 \%)$ \\
Age & Mean & 45 \\
& Range & $20-72$ \\
\hline
\end{tabular}

Table 2. Distribution of patients with aneurysmal SAH by artery of origin.

\begin{tabular}{ll}
\hline Artery of origin & $\begin{array}{l}\text { Number of } \\
\text { patients } \\
(\% \text { of total) }\end{array}$ \\
\hline Anterior comunicating & $22(42.3)$ \\
Posterior communicating & $15(28.8)$ \\
\hline Middle cerebral & $5(9.6)$ \\
Terminal internal carotid & $4(7.7)$ \\
\hline Ophthalmic & $2(3.9)$ \\
Supraclinoid internal carotid & $1(1.9)$ \\
\hline Multiple locations & $1(1.9)$ \\
Basilar tip & $2(3.9)$ \\
\hline
\end{tabular}

Table 3. Results obtained from the protocol for cerebral vasospasm used to manage 52 patients suffering from aneurysmal subarachnoid hemorrhage.

\begin{tabular}{lc}
\hline Outcome & $\%$ of total \\
Symptomatic vasospasm & $13(25.0)$ \\
Severe disability & $3(5.8)$ \\
\hline Mild disability & $2(3.9)$ \\
Mortality rate from vasospasm & $4(7.7)$ \\
\hline
\end{tabular}

against CV. All patients were admitted to the intensive care unit. Intravenous fluids were commenced at a rate of $1.7 \mathrm{~mL} / \mathrm{kg} / \mathrm{h}$ of normal saline $0.9 \%$ versus glucose water $5 \%$. Systolic blood pressure was maintained between 120 and $160 \mathrm{mmHg}$ and raised up to 180 as indicated in patients with secured aneurysm. Oxygen saturation was maintained at $>95 \%$ for at least 14 days and longer if vasospasm developed. Nimodipine was given for 21 days as an intravenous infusion of $20 \mathrm{mcg} / \mathrm{kg} / \mathrm{h}$ from the day of admission for up to two weeks, and then continued at $60 \mathrm{mg} / 4 \mathrm{~h}$ orally for another week if there was no evidence of vasospasm. In the presence of vasospasm, nimodipine was continued intravenously for 21 days. $\mathrm{MgSO}_{4} 20$ $\mathrm{mEq} / \mathrm{L}$ in $0.9 \%$ Normal saline was also given to maintain the serum magnesium double the normal level between 1.5 and $2 \mathrm{mmol} / \mathrm{L}$ for 10 14 days (average $40-80 \mathrm{mEq} / \mathrm{d}$ ).

When patients developed symptoms suggestive of clinical vasospasm, a non-contrast CT scan was repeated to rule out re-bleeding, hydrocephalus cerebral edema, or ischemic changes. Patients with a significant decline in

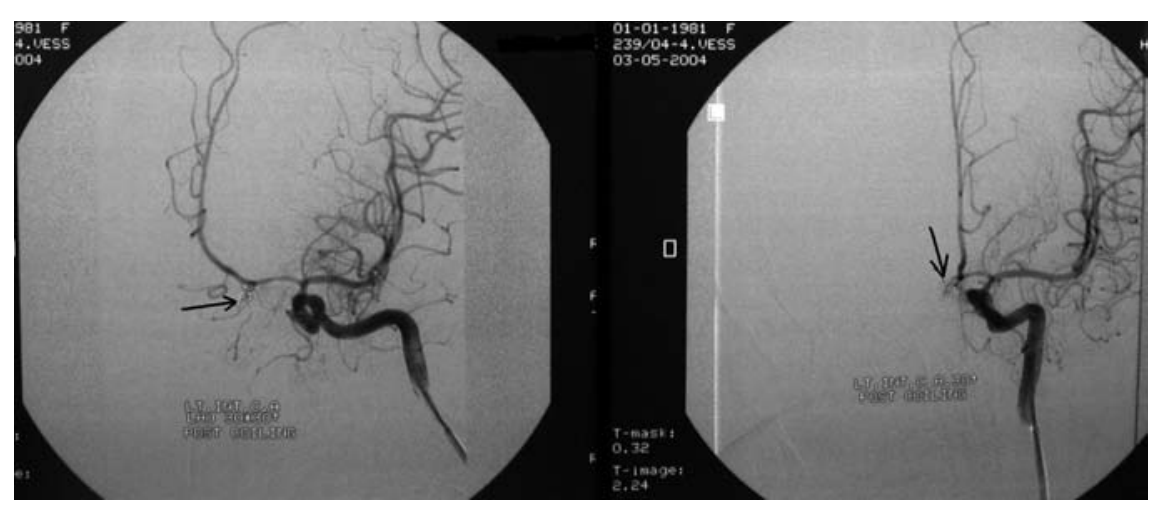

Figure 1. DSA (AP) views of a 20 year old woman presenting with symptomatic vasospasm, showing severe vasospasm. The arrow indicates the coiled anterior communicating artery aneurysm. Although all treatment options were used, she continued to decline until death.

level of consciousness (GCS fall of more than two points) were intubated, ventilated and sedated using morphine and midazolam at a rate of $5 \mathrm{mg} / \mathrm{h}$ each. Intracranial pressure (ICP) was monitored on all intubated patients.

For all patients with new symptoms suggestive of vasospasm, with a negative CT scan and no metabolic disorders to explain the symptoms, cerebral angiography was repeated to confirm the diagnosis and to reverse the narrowed segments with selective injection of vasodilators (papaverine vs. nimodipine) into the cerebral arteries in spasm. Intraarterial vasodilators was repeated for patients with persistent vasospasm. Transluminal balloon angioplasty was also used when necessary in patients with symptomatic proximal vasospastic segments who did not respond to the medical treatment.

Although not a specific treatment option for $\mathrm{CV}$, administration of barbiturates has been applied in the management of patients in our department who continued to display refractory cerebral vasospasm with a significant decline in conscious level (GCS below 9/15) and intractable high ICP to provide adequate cerebral protection during vasospasm. When required, intravenous sodium thiopental (STP) was used at a rate of $3-4 \mathrm{mg} / \mathrm{kg} / \mathrm{h}$ after a bolus dose of $10 \mathrm{mg} / \mathrm{kg}$ over one hour, with therapeutic endpoint being control of ICP or its side effects such as sepsis or hypotension.

\section{Results}

Using this protocol, 13 (25\%) of the 52 patients admitted with aneurysmal subarachnoid hemorrhage had symptomatic vasospasm requiring aggressive treatment ( 8 males, 5 females; male:female ratio 1.6:1). Three patients were Fisher grade 2, 7 patients grade
3 , and the rest grade 4 . The anterior communicating artery was the site of ruptured aneurysm in 8 patients with clinical vasospasm (Figure 1), while the posterior communicating, terminal carotid and middle cerebral arteries were the origin in 5 cases. Six patients required intraarterial vasodilators for prolonged vasospasm. Transluminal balloon angioplasty was successfully performed in 3 patients (Figure 2A and B). Ten patients received barbiturates; administration was stopped early in 2 , the first a young woman who developed fixed dilated pupils on the following day and the other a patient who sustained a high fever with leukocytosis after two days. He continued to decline until he died from vasospasm three days later. STP was used for 1-5 (average 3.5) days.

\section{Patient outcomes}

Four, all of whom had anterior communicating artery aneurysm, of the 52 patients (7.7\%) died of severe vasospasm. Another 6 patients (11.5\%) died of other causes, 3 from re-bleeding, 2 from pulmonary embolism and one from sepsis, giving an overall mortality rate of $19.2 \%$. Three patients (5.8\%) survived with significant disability requiring ongoing nursing care (Figure 3A and $\mathrm{B}$ ). The remaining patients $(75 \%)$ were discharged in either normal condition or with minor neurological deficit. Two patients experienced mild hemiparesis and sensory changes which recovered well over time (Table 3). However, some patients experienced variable clinical signs identical to those of symptomatic vasospasm. One developed a progressive decline in conscious level; CT scan revealed active communicating hydrocephalus but he made a good recovery after placement of a ventriculo-peritoneal shunt. Another patient became depressed with behavioral changes. Investigative tests resulted normal and she respond- 
ed well to antidepressant medication. Another developed grand mal seizures after his full recovery from severe vasospasm and he is maintained on anticonvulsant medications.

\section{Discussion}

Symptomatic cerebral vasospasm is the most significant cause of high mortality and morbidity in patients suffering aneurysmal $\mathrm{SAH}$. It ranges in severity from mild and reversible to severe, leaving disabling deficits from ischemic changes in $7 \%$ of affected patients. Vasospasm can be severe enough to cause infarction and death in another $7 \%$ of patients. Angiographic vasospasm after ruptured aneurysm occurs in $30-70 \%$ of patients, while symptomatic vasospasm is seen in about one third of cases. ${ }^{11}$

The etiology of vasospasm is still under debate; the mechanism is related to the arterial blood clot and its spasmogenic products. ${ }^{12}$ Oxyhemoglobin and free radicals produced by lysed red cells result in noxious effects on the endothelial cells and smooth muscle of the arterial wall. An influx of calcium ions and protein kinase $\mathrm{C}$ are implicated in the release of vasoconstricting substances, which leads to significant structural changes in the arterial wall including smooth muscle and myofibroblast proliferation, cellular necrosis, intimal hyperplasia and fibrosis, resulting in vasoconstriction. Removal of the blood clot and its products has been proposed to prevent these changes but the efficacy of this treatment has not been proven. However, calcium concentration in endothelial and smooth muscle cells may play a part in the pathogenesis of cerebral vasospasm. ${ }^{13-18}$ Increased nitric oxide in the CSF may play a role in the development of CV through a free radical-mediated injury of the endothelial cell membrane. ${ }^{19}$

One of the most recent vasoconstricting mediators is endothelin (ET-1) which is produced by the endothelial cells. It interacts with endothelin receptors located on smooth muscle cells and triggers vasoconstriction and proliferation of endothelial and smooth muscle cells. $^{20,21}$ Recent studies have focused on discovering an effective antagonist to the endothelin receptors to block the cascade of the arterial wall reactions. ${ }^{22}$ Nevertheless, prolonged CV can be explained by the biomechanical and phenotypic reactions in response to $\mathrm{SAH}$ rather than from myogenic changes in the arterial wall. ${ }^{23,24}$

Numerous diagnostic tools and treatment options of vasospasm now exist. Most recent treatment modalities utilized can be grouped into direct or indirect pharmaceutical and mechanical vasodilators and neuroprotective agents. ${ }^{24-26}$ Further clinical trials are still need-
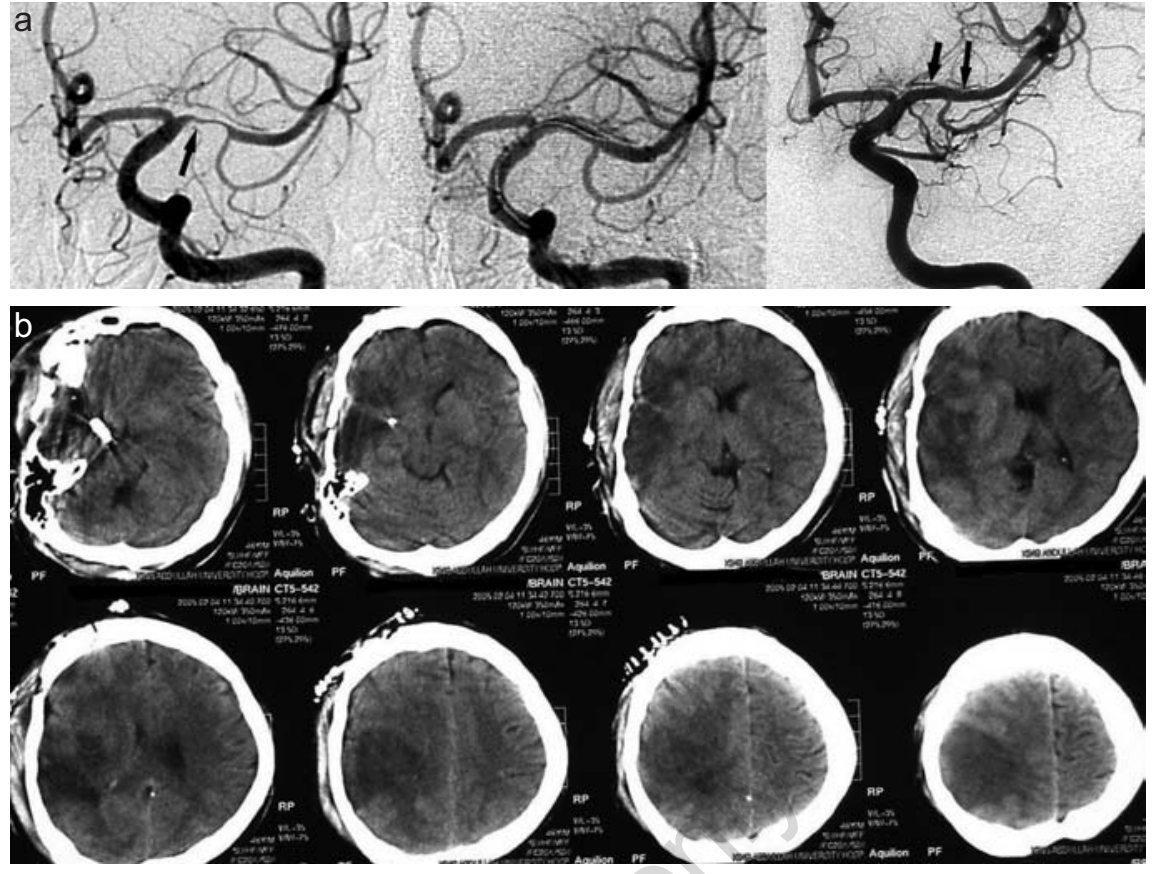

Figure 2. (a) DSA (AP) views pre- and post balloon angioplasty of a young patient suffering severe vasospasm. Narrowing of the anterior cerebral artery can be seen in the pre- balloon angioplasty figures (one arrow); the same artery dilated post balloon angioplasty ( 2 arrows). (b) CT scan of the same patient after recovery from cerebral vasospasm showing R. fronto-parietal ischemic changes. His residual deficits are mild hemiparesis and sensory disturbance.

ed to establish standard guidelines for the management of CV. Several diagnostic techniques have been used to predict $\mathrm{CV}$. Computed tomography scanning (CT) is considered an important initial method for the prediction of vasospasm and its consequences. The large amount of blood on the initial CT scan is known to be a prognosticator of ischemia or even infarction from arterial vasospasm. ${ }^{4}$ Transcranial doppler sonography (TCD) can detect increased velocities in the basal segments of the anterior or posterior circulations. A rapid rise in velocity in the artery is usually associated with symptomatic vasospasm. Although it is feasible and noninvasive, TCD is less accurate than cerebral angiograghy in confirming vasospasm. It should be used to follow the progress of vasospasm. ${ }^{27,28}$

Although it is invasive, cerebral angiography is still the most accurate and standard tool for the diagnosis of vasospasm in addition to its value for endovascular treatment. ${ }^{28} \mathrm{New}$ technologies such as CT perfusion scan, single photon emission computed tomography (SPECT) and magnetic resonance perfusion and diffusion scans may be employed to identify early ischemic foci in the brain before clinical vasospasm arises. ${ }^{12}$

Triple-H therapy consisting of hypervolemia, hemodilution and hypertension is a treatment designed to enhance cerebral blood flow (CBF) in ischemic zones and lower blood viscosity. It has been shown to offer benefits in many series, but it may not reduce overall morbidity and mortality. Increased blood volume can be obtained by using volume expanders or crystalloid fluids. Hemodilution can frequently occur passively with an optimum hematocrit goal of between $30 \%$ and $33 \%$ without affecting $\mathrm{O}_{2}$ carrying capacity. Elevating the systemic blood pressure can be introduced by volume expansion or pressors. Inducing hypertension may be risky with an unsecured aneurysm. It is necessary to monitor hemodynamics via appropriate indwelling catheters. The end point of triple-H therapy is significant brain edema or large infarction. ${ }^{29.31}$

The calcium entry blocking agent nimodipine has preferential cerebrovascular dilating effects, with potential use in the therapy and prevention of CV after aneurysmal SAH as it protects against delayed ischemic damage. Continuous infusion of nimodipine (20 $\mathrm{mcg} / \mathrm{kg} / \mathrm{h}$ ) is initially given on admission and continued for 21 days. However, oral nimodipine (60 mg every four hours) can be continued for 21 days in the absence of clinical vasospasm. Nimodipine has been shown to decrease the incidence of $\mathrm{CV}$ and improve neurological outcome. ${ }^{32-34}$ Selective intraarterial nimodipine treatment is currently being suggested as a safe and effective treatment for $\mathrm{CV}^{35-36}$ Intraoperative nimodipine infusion has also been trialled to prevent $\mathrm{CV}$ during intracranial aneurysm surgery with promising 
results..$^{37}$ More recently, interest has emerged in the use of magnesium sulphate $\left(\mathrm{MgSO}_{4}\right)$ as a neuroprotectant in obstetric patients with eclampsia and as a cerebral vasodilator for vasospasm. The role of $\mathrm{MgSO}_{4}$ in preventing vasospasm is questionable, but it may augment $\mathrm{CBF}$ by inducing vasodilatation. ${ }^{38}$ Evidence obtained from experimental models of brain injury, stroke and SAH indicates that magnesium ions play a significant role as neuroprotective agents. Continuous infusion of high-dose magnesium has been suggested to prevent and treat delayed ischemic neurological deficit (DIND) in patients after ruptured aneurysm. ${ }^{39-41}$ The optimum therapeutic dose of $\mathrm{MgSO}_{4}$ is unknown, but continuous infusion of $64 \mathrm{mmol} / \mathrm{L} /$ day for 14 days after aneurysmal surgery has been shown to reduce the risk of vasospasm by $34 \%$ and improve outcome. Moreover, $\mathrm{MgSO}_{4}$ infusion which elevates the serum magnesium concentration to substantial therapeutic levels is well tolerated and safe, and has no major hemodynamic effects in patients with DIND. ${ }^{42-45}$

When aggressive medical therapy fails to reverse ischemic deficits, prompt endovascular intervention is indicated. ${ }^{46}$ Vasospasm involving smaller arterial branches may be treated with an intraarterial infusion of vasodilators. Intraarterial papaverine is widely used; it produces clinical improvement in $43 \%$ of patients, augments CBF in another $60 \%$ of patients, and mean TCD velocities are improved. However, increased intracranial pressure, marked neurological deterioration and other complications are experienced with this mode of treatment, reaching $10 \%$ in some series. Overall supra selective intraarterial papaverine infusion is still highly recommended. ${ }^{47-49}$ Unfortunately, this dilatory effect tends to be short-lasting and requires repetition in cases of persistent vasospasm to improve CBF and outcomes..$^{50}$ Nicardipine, another vasodilating agent, has also been trialled. Endovascular nicardipine therapy produced clinical improvement in $42 \%$ of patients, with significant improvement of mean TCD velocities, but only for four days. It was recommended as an endovascular treatment protocol for refractory vasospasm but this requires further evaluation. ${ }^{46,51}$

Proximal vasospasm of larger vessels may be effectively treated with intraluminal balloon angioplasty. The benefit of this procedure is durable compared with intraarterial vasodilators. Clinical series assessing transluminal balloon angioplasty indicate clinical improvement in $62 \%$ of patients, and considerably improved mean transcranial Doppler (TCD) velocities and CBF in $85 \%$ of patients as studied by Xenon 133 techniques and serial SPECT. Although it is efficient in treating the artery in spasm it may cause arterial rupture in $1.1 \%{ }^{52,53}$

Controlled neuro-intensive management with endovascular techniques are integrated
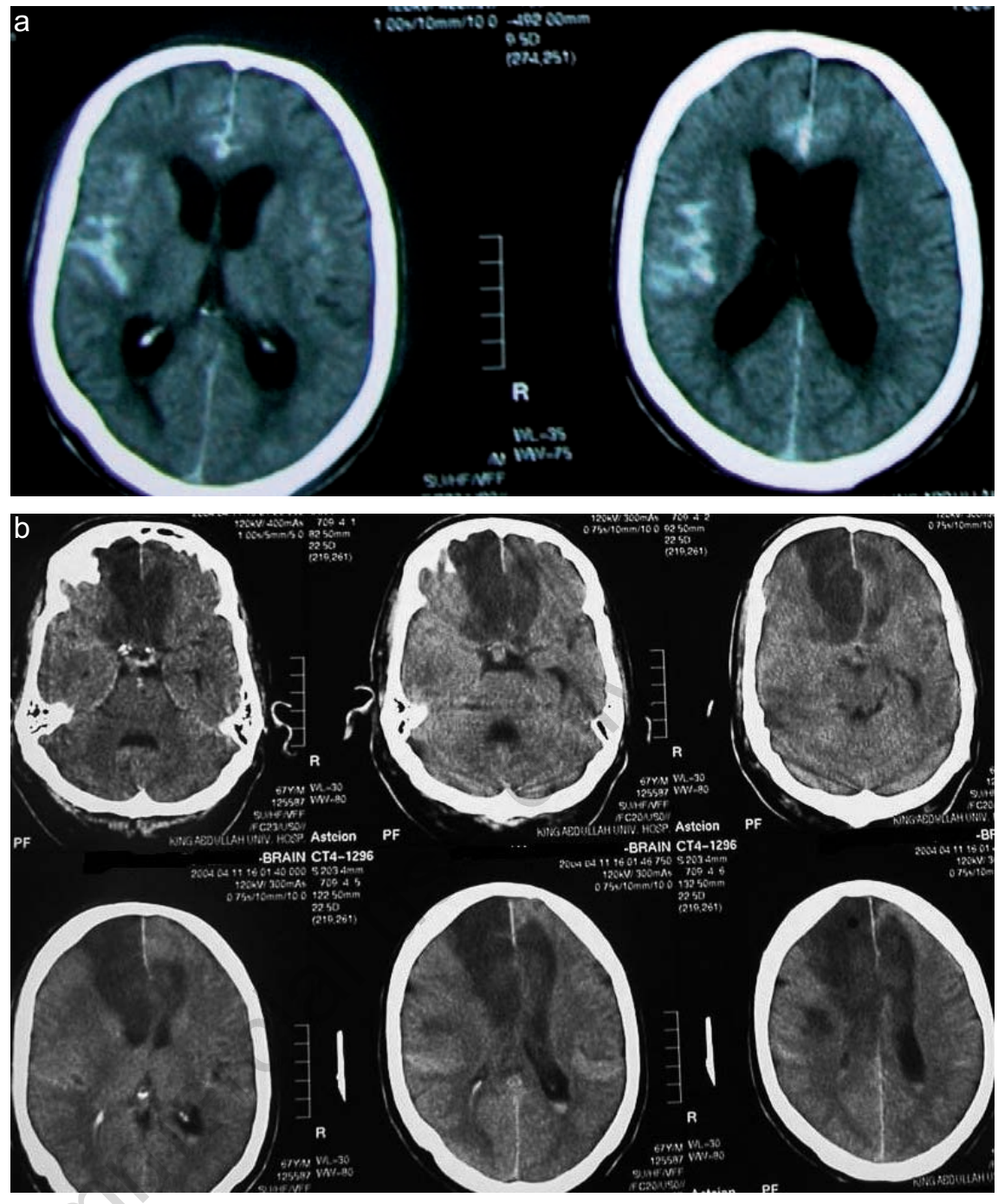

Figure 3. (a) CT scan of a 55 year-old man showing a large amount of blood in the subarachnoid space (Fisher grade 3). (b) CT scan of the same patient revealed bifrontal infarction from severe bilateral ACA vasospasm. Although he had aggressive medical and surgical treatment for vasospasm he was left with severe disability.

in protocols rather than alternative methods for the treatment of imminent vasospasm. However, poor results are seen in patients with high clinical grades at the onset of SAH and advanced age, despite aggressive endovascular treatment. ${ }^{25,54,55}$

Barbiturate-induced coma can be of help in patients with vasospasm which is refractory to other therapies, to prevent life threatening neurological deficit. Barbiturates can ameliorate the harmful consequences of cerebral ischemia from vasospasm by reducing the neuronal metabolic rate and decreasing $\mathrm{O}_{2}$ consumption. Barbiturate therapy has shown an improvement in $45 \%$ of patients with no related deaths reported. Cardiovascular depression and sepsis are the major concerns for barbiturate use. ${ }^{56}$ Pentobarbital sodium is the most active cerebral vasodilator in this class of anesthetics. This agent inhibits the vasospastic activity of potassium, serotonin, and prostaglandins, and appears to be a calcium entry antagonist in the blood vessels. Cerebral perfusion pressure should be controlled by the use of vasopressors to offset the hypotensive effect of barbiturates. Barbiturate therapy is continued as long as vasospasm persists with high ICP. Therapeutic end point is ICP control. Following these guidelines, administration of barbiturates is believed to achieve good results. ${ }^{57-60}$

More recently, promising results from the use of the endothelin A (ETA) receptor antagonist clazosentan may create new options for treatment of $\mathrm{CV}^{21}$ Moreover, the probable role of E-selectin in the pathogenesis of vasospasm and the use of anti-E-selectin monoclonal antibody may help treatment. Further trials are required to confirm these results. ${ }^{61}$ 


\section{References}

1. Oertel M, Boscardin WJ, Obrist WD, et al. Post traumatic vasospasm: the epidermiology, severity, and time course of underestimated phenomenon: a prospective study performed in 299 patients. J Neurosurg 2005;103:812-24.

2. Findlay JM, Macdonald RL, Weir BKA. Current concepts of pathophysiology and management of cerebral vasospasm following aneurysmal subarachnoid hemorrhage. Cerebrovasc Brain Metab Rev 1991;3:336-61.

3. Oshiro EM, Walter KA, Piantadosi S, et al. A new subarachnoid grading system based on the Glasgow Coma Scale: A comparison with Hunt and Hess World Federation of Neurosurgical Surgeons Scales in a clinical series. Neurosurgery 1997;41:140-7.

4. Fisher CM, Kistler JP, Davis JM. Relation of cerebral vasospasm to subarachnoid haemorrhage visualized by computed tomographic scanning. Neurosurgery 1980;6:1-9.

5. Macdonald RL, Rosengart A, Huo D, Karrison T. Factors associated with the development of vasospasm after planned surgical treatment of aneurysmal subarachnoid hemorrhage. J Neurosurg 2003;99:644-52.

6. Weir BKA, Macdonald RL, Stoodly M. Etiology of cerebral vasospasm. Acta Neurochir Suppl.1999;72:27-46.

7. Weir BKA. The incidence and onset of a vasospasm after subarachnoid hemorrhage from ruptured aneurysm, in Wilkins RH (Ed): Cerebral Arterial Vasospasm. Baltimore, Williams \& Wilkins 1980;302-5.

8. Dorsch NW. Therapeutic approaches to vasospasm in subarachnoid hemorrhage. Curr Opin Crit Care 2002;8:128-33.

9. Wikins RH. Attempts at prevention or treatment of intracranial arterial spasm: an update. Neurosurgery 1986;18:808-25.

10. Komotar RJ, Zacharia BE, Valhora R, et al. Advances in vasospasm treatment and prevention. J Neurol Sci. 2007;261:134-42

11. Kassell NF, Sasaki T, Colohan ART, Nazar G. Cerebral vasospasm following aneurysmal subarachnoid haemorrhage. Stroke 1985;16:562-72.

12. Harrod CG, Bendok Bernard RB. Prediction of cerebral vasospasm in patients presenting with aneurysmal subarachnoid hemorrhage: a review. Neurosurgery 2005;56:633-54.

13. Dietrich HH, Dacey RG. Molecular keys to the problems of cerebral vasospasm. Neurosurgery 2000;46:517-30.

14. Macdonald RL, Weir BKA. A review of hemoglobin and pathogenesis of cerebral vasospasm. Stroke 1991;22:971-82.
15. Smith RR, Clower BR, Grotendorst GM, et al. Arterial wall changes in early human vasospasm. Neurosurgery 1985;16:171-6.

16. Melon E. Pathophysiology and principles of treatment of vasospasm. J Neuroradiol 1999;26:30-5.

17. Paschen W. Role of calcium in neuronal cell injury: which subcellular compartment is involved? Brain Res Bull 2000;53:409-13.

18. Lefranc F. Cerebral vasospasm: molecular analysis. Bull Mem Acad R Med Belg 2003; 158:258-64.

19. Woszczyk A, Deinsberger W, Boker DK. Nitric oxide metabolites in cisternal CSF correlate with cerebral vasospasm in patients with a subarachnoid haemorrhage. Acta Neurochir (Wien) 2003;145:257-63.

20. Juvela S. Plasma endothelin concentrations after subarachnoid hemorrge. J Neurosurg 2000;92:390-400.

21. Vajkoczy P, Meyer B, Weidauer S, et al. Clazosentan (AXV-034343), a selective endothelin A receptor antagonist, in the prevention of cerebral vasospasm following severe aneurismal subarachnoid hemorrhage: results of a randomized, doubleblind, placebo-controlled, multicenter phase Ila study. J Neurosurg 2005;103: 917.

22. Chow M, Dumont AS, Kassell NF. Endothelin receptor antagonists and cerebral vasospasm: an update. Neurosurgery 2002; 51:1333-42.

23. Yamaguchi-Okada M, Nishizawa S, Koide M, Nonaka Y. Biomechanical and phenotypic changes in the vasospastic canine basilar artery after subarachnoid hemorrhage. J Appl Physiol 2005;99:2045-52.

24. Janjua N, Mayer SA. Cerebral vasospasm after subarachnoid hemorrhage. Curr Opin Crit Care 2003;9:113-9.

25. Schuknecht B. Endovascular treatment of cerebral vasospasm following aneurysmal subarachnoid hemorrhage. Acta Neurochir Suppl 2005;94:47-51.

26. Shatalov VI, Shchegolev AV. Effect of infusion therapy on central hemodynamics and the outcome of treatment in patients with subarachnoidal hemorrhages. Anesteziol Reanimatol 2005;4:55-8.

27. Seiler RW, Grolimund P, Aaslid R, Huber P, Nornes $H$. Cerebral vasospasm evaluated by transcranial ultrasound correlated with clinical grades and CT visualized subarachnoid haemorrhge. J Neurosurgery 1995;82:55-62. [FullText]

28. Lindegaard KF. Nornes H, Bakke SJ, et al. Cerebral vasospasm diagnosis by means of angiographic and blood velocity measurements. Acta Neurochir (Wien) 1989;100:12-24.

29. Gupta D, Sharma BS, Gupta SK, et al. Postoperative hypertensive-hypervolaemic -haemodilution (Triple $\mathrm{H}$ ) therapy in the treatment of vasospasm following aneurysmal subarachnoid haemorrhage. Neurol India 2000;48:126-31.

30. Kassell NF, Peerless SJ, Durward QJ et al. Treatment of ischemic deficits from vasospasm with intravascular volume expansion and induced arterial hypertension. Neurosurgery 1982;11:337-43.

31. Treggiari MM, Walder B, Suter PM, Romand JA. Systematic review of the prevention of delayed ischemic neurological deficits with hypertension, hypervolemia, and hemodilution therapy following subarachnoid hemorrhage. J Neurosurg 2003;98:978-84.

32. Rabinstein AA, Wijdicks EF. Cerebral Vasospasm in Subarachnoid Hemorrhage. Curr Treat Options Neurol 2005;7:99-107.

33. Stullken EH Jr, Johnston WE, Prough DS, et al. Implications of nimodipine prophylaxis of cerebral vasospasm on anesthetic management during intracranial aneurysm clipping. J Neurosurg 1985; 62:200-5.

34. Wu CT, Wong CS, Yeh CC, et al. Treatment of cerebral vasospasm after subarachnoid hemorrhage-a review. Acta Anaesthesiol Taiwan 2004;42:215-22.

35. Biondi A, Ricciardi GK, Puybasset L, Borel CO. Intra-arterial nimodipine for the treatment of symptomatic cerebral vasospasm after aneurysmal subarachnoid hemorrhage: preliminary results. AJNR Am J Neuroradiol 2004; 25:1067-76.

36. Hui C, Lau KP. Efficacy of intra-arterial nimodipine in the treatment of cerebral vasospasm complicating subarachnoid haemorrhage. Clin Radiol 2005;60:1030-6.

37. Han RQ, Wang BG, Li SR, et al. The effect of intraoperative continuous nimodipine infusion on cerebral vasospasm during intracranial aneurysm surgery. Chinese J Surg 2004;42:1489-92.

38. Muir KW, Lees KR. A randomized, doubleblind, placebo-controlled pilot trial of intravenous magnesium sulfate in acute stroke. Stroke 1995;26:1183-8.

39. Collignon FP, Friedman JA, Piepgras DG, et al. Serum magnesium levels as related to symptomatic vasospasm and outcome following aneurysmal subarachnoid hemorrhage. Neurocritical Care 2004;1:441-8.

40. Macdonald RL, Curry DJ, Aihara Y, et al. Magnesium and experimental vasospasm. J Neurosurgery 2004;100:106-11.

41. Veyna RS, Seyfried D, Burke DG, et al. Magnesium sulfate therapy after aneurysmal subarachnoid hemorrhage. J Neurosurgery 2002;96:510-4.

42. Keith WM, Kennedy RL. Dose optimization of intravenous magnesium sulfate after acute stroke. Stroke 1998;29: 918-23.

43. Yahia AM, Kirmani JF, Qureshi AI, et al. 
The safety and feasibility of continuous intravenous magnesium sulfate for prevention of cerebral vasospasm in aneurysmal subarachnoid hemorrhage. Neurocrit Care 2005;3:16-23.

44. van den Bergh WM, Algra A, Van KF, et al. Magnesium sulfate in aneurysmal subarachnoid hemorrhage: a randomized controlled trial. Stroke 2005;36:1011-5.

45. Chia RY, Hughes RS, Morgan MK. Magnesium: a useful adjunct in the prevention of cerebral vasospasm following aneurysmal subarachnoid haemorrhage.

J Clin Neurosci 2002;9: 279-81.

46. Hoh BL, Ogilvy CS. Endovascular treatment of cerebral vasospasm: transluminal balloon angioplasty, intra-arterial papaverine, and intra-arterial nicardipine. Neurosurg Clin N Am 2005;16:501-16.

47. Clouston JE, Numaguchi Y, Zoarski GH, et al. Intra-arterial papaverine infusion for cerebral vasospasm after subarachnoid hemorrhage. AJNR Am J Neuroradiol 1995;16:27-38.

48. Kaku Y, Yonekawa Y, Tsukahara T, Kazekawa K. Superselective intra-arterial infusion of papaverine for the treatment of cerebral vasospasm after subarachnoid hemorrhage. J Neurosurg 1992;77:842-7.

49. Smith WS, Dowd CF, Johnston SC, et al. Neurotoxicity of intra-arterial papaverine preserved with chlorobutanol used for the treatment of cerebral vasospasm after aneurysmal subarachnoid hemorrhage. Stroke 2004;35:2518-22.

50. Liu JK, Tenner MS, Gottfried ON, et al. Efficacy of multiple intra-arterial papaverine infusions for improvement in cerebral circulation time in patients with recurrent cerebral vasospasm. J Neurosurg 2004; 100:414-21.

51. Badjatia N, Topcuoglu MA, Pryor JC, Rabinov JD. Preliminary experience with intra-arterial nicardipine as a treatment for cerebral vasospasm. AJNR Am J Neuroradiol 2004; 25:819-26.

52. Murai Y, Kominami S, Kobayashi S, et al. The long term effects of transluminal balloon angioplasty for vasospasm after subarachnoid hemorrhage: analysis of cerebral blood flow and reactivity. Surg Neurol 2005;64:122-6.

53. Zubkov Y, Nikiforov BM, Shustin VA. Balloon catheter technique for dilatation of constricted cerebral arteries after aneurysmal subarachnoid hemorrhage. Acta Neurochir 1984;70:65-79.

54. Morgan MK, Jonker B, Finfer S, et al. Aggressive management of aneurysmal subarachnoid haemorrhage based on a papaverine angioplasty protocol. J Clin Neurosci 2000;7:305-8.

55. Rabinstein AA, Friedman JA, Nichols DA, et al. Predictors of outcome after endovascu- lar treatment of cerebral vasospasm. AJNR Am J Neuroradiol 2004;25:1778-82.

56. Selman WR, Spetzler RF. Therapeutics for focal cerebral ischemia. Neurosurgery 1980;6:446-52.

57. Altura BM, Altura BT. Pharmacologic inhibition of cerebral vasospasm in ischemia, hallucinogen ingestion, and hypomagnesemia: barbiturates, calcium antagonists, and magnesium. Am J Emerg Med 1983;1:180-90.

58. Kassell NF, Peerless SJ, Drake CG, et al. Treatment of ischemic deficits from cerebral vasospasm with high dose barbiturate therapy. Neurosurgery 1980;7:593-7.

59. Miyagi K, Ishijima B, Sato F, et al. Indication for, the method of, and result of the prophylactic use of barbiturate therapy (B-therapy) against cerebral infarct from cerebral arterial vasospasm due to ruptured aneurysm. No Shinkei Geka 1984; 12:303-10.

60. Cordato DJ, Herkes GK, Mather LE, et al. Barbiturates for acute neurological and neurosurgical emergencies - do they still have a role? J Clin Neurosci 2003;10:283-8.

61. Lin CL, Dumont AS, Calisaneller T, et al. Monoclonal antibody against $\mathrm{E}$ selectin attenuates subarachnoid hemorrhageinduced cerebral vasospasm. Surg Neurol 2005;64:201-5. 